\title{
Product Mix Optimization for an Oil Field Operating Company
}

\author{
Najla Abdulaziz Khonji ${ }^{1}$ \& Saad M. A. Suliman ${ }^{2}$ \\ ${ }^{1}$ Tatweer Petroleum, Bahrain \\ ${ }^{2}$ College of Engineering, University of Bahrain, Bahrain \\ Correspondence: Saad M. A. Suliman, College of Engineering, University of Bahrain, P. O. Box 32038, Isa \\ Town, Bahrain.
}

Received: July 23, 2020

doi:10.5539/mas.v14n10p20
Accepted: September 14, 2020

Online Published: September 24, 2020

\begin{abstract}
In this study, a mathematical model is formulated to select the optimal product mix of wells in terms of numbers and types of wells that helps to maximize profit. The optimization model comprises two main components, the first component is revenue which includes forecasting of production and oil price, and the second component is cost which includes capital and operating costs. In addition, the model considers all related constraints such as budget, production targets, surface facility limitations, drilling rigs availability and others. Time has influence on the model, since its output is not limited only to the types and numbers of wells to be drilled during the planned period, but also when each well to be drilled for the same plan. Actual planning data for three consecutive years is used for model testing. The results show that $42 \%$ to $47 \%$ cost saving can be achieved by using the model. The analysis shows that with every $10 \%$ increase in oil price, the profit increases by about $6 \%$. Also, it shows that the number of rigs and the rig daily cost affect the profit tremendously, where by reducing these two parameters by $50 \%$ an increase of $66 \%$ in oil profit can be achieved. The study confirms that oil field operating companies can stand a better chance of maximizing their profit by using product mix optimization model to define the optimum schedule for the number of wells, type of wells and time of drilling.
\end{abstract}

Keywords: profit optimization, product mix, drilling scheduling, oil operating companies

\section{Introduction}

Oil field operating companies are apparently producing one single product which is oil but in reality there are many different types and categories of oil which involve different cost to produce and subsequently different price at market. This entails a need to decide on the product mix similar to what manufacturing companies do. Oil can be categorized based on two factors: first is the oil API (American Petroleum Institute) gravity such as heavy, medium or light where the selling price associated with each is different, and second is how easy or difficult to produce such oil where different techniques are involved which has a direct impact on cost. There is a potential for product mix optimization by drilling the optimum number of wells for each reference (specified by reservoir, well type and crude oil grade) where each well is associated with oil production rates and costs. It is very important to realize that it is not a onetime cost paid at the time of drilling but there is a maintenance and operating cost associated with each barrel produced. Furthermore, oil price fluctuation and declining oil production per well with time must be considered.

Currently, companies use partial optimization of the wells to be drilled with limited consideration to time, and they focus on production maximization instead of profit maximization with a misleading assumption that maximizing profit can be achieved by maximizing the production through accelerated drilling. Pursuing this assumption will lead to a limited optimized plans that only define the maximum number of wells and type of wells to be drilled and ignoring the significant impact of the timing. In addition, the manual optimization approach can't handle all constraints and it is very time consuming process. Subsequently, a maximized profit cannot be achieved or guaranteed for the shareholders by using such approach. These difficulties can be eliminated by using an appropriate automated optimization model that is formulated based on the fact that maximizing the profit is guaranteed by optimizing the production through product mix optimization. Such model handles all constraints, and defines the optimum number of wells of specific reference and when each will be drilled during the planning period. 
This study presents a model that maximizes the profit of an oil field operating company through product mix optimization. The model is automated using MATLAB code. The results obtained by applying the model to actual planning data show considerable cost savings.

\section{Literature Review}

As early as 1950s, optimization techniques have been implemented in the upstream oil industry, it covers different sub-fields including recovery processes, planning, history matching, well placement, drilling, facility design and operation etc. This have been an active area for optimization in the oil and gas industry. Lee and Aronofsky (1957) built a linear programming model to maximize profit by scheduling production from multiple homogeneous reservoirs. The limitation of the study is the assumption that profit is known for the period of scheduling without considering the oil price and cost involved. Also, the model is limited to reserves and facilities constraints only. Aronofsky (1983) reviewed the application of linear programming in oil and gas development, and extended his work to include mixed integer programming. He considered in his model the field production rate profile, flow rate of wells, number of new wells and their production schedule. But he didn't consider the effect of reservoir, oil grade and price fluctuation. Van Leeuwen and Chow (1989) build a profit maximization model for a gas field by considering revenue and cost, in addition to tax and royalty. The constraints in their model are production target (demand) and facilities available. Arnondin (1995) focused on maximizing production, instead of profit, with one constraint only which is facility handling capacity and focusing on existing wells and not considering future drilling of wells. The model can be used for daily production maximization and not future planning.

Mora et al. (2005) worked on maximizing net present value (NPV) in a mature oil field by optimizing the gas lift operations. They used integrated mathematical models to describe the behavior of the reservoir, the fluid and gas lift gathering system and the future economic performance. Their approach is in contrast to those in current use that seek either maximize oil production rate or maximize gas lift efficiency of individual wells. The idea of drilling maximum number of wells that produce maximum amount of oil may not necessarily achieve maximum profit, and developing the reservoirs in a parallel fashion rather than sequential may not be the right way as concluded in a research carried by Vasantharajan et al. (2006). Irgens and Lavenue (2007) and Irgens et al. (2007) conducted a case study in Saudi Aramco where the number of drilling and workover rigs increased significantly. This caused an exponential growth in the challenge of scheduling the rigs use and transportation. A software application was developed and used for rig scheduling which improves the daily decisions and optimizing of both operational and strategic objectives. Atnagulov et al. (2010) developed optimization methods of profitability assessment and well cluster drilling with account of capital expenditure. They used the well clustering approach to develop the field through three modules: reservoir engineering module; surface module; and economic module. Huang et al. (2012) build simple models for the reservoirs, wells, surface flowlines and facilities to optimize trade-off between spare production capacity and drilling schedule in order to reduce cost.

In order to maximize the profit, the oil price is a critical parameter to achieve the goal. Therefore, appropriate oil price forecast model is required. Behmiri and Manso (2011) and Gabralla and Abraham (2013) conducted a comprehensive review on oil price forecasting literature. Bukhari and Jablonowski (2012) studied the effect of different oil price models on oil production optimization. Five oil price models between deterministic and probabilistic approaches were used. Their results showed that the optimum production to achieve the maximum NPV is the same regardless of the model used. Manescu and Robays (2014) presented nine different individual oil price forecasting methods. Some of their models were used by Pagano and Pisani (2009) who found that risk-adjusted future models provide a more precise forecast than the others for more than 6 months forecasting period.

Beside oil price, oil production forecast plays a tremendous effect on predicting profit. There are many techniques available in the industry used for this purpose, and the most popular one is Decline Curve Analysis (DCA). Rahuma et al. (2012) and Rahuma et al. (2013) adopted the Arps equations (Arps is the developer of the DCA model) for prediction of reservoir performance. Makinde et al. (2012) indicated that DCA and Arps equations have limitation, and using either exponential or hyperbolic decline might be unrealistic in forecasting. They presented a more accurate approach by combining exponential and hyperbolic declines into one new model. Darwis et al. (2009) used DCA to develop three models by using historical data and least squares techniques. Peak oil models forecast is another way of predicting future oil production and oil reserves, several models are available that uses this approach (Lianyoung et al. (2008); Wang et al. (2011)). Despite the value of these researches, they are not used in this paper for oil production forecast due to the unavailability of reservoir data, and complexity of implementation. Most of the studies and researches on oil production forecast use DCA, therefore it is used in this study as one of the inputs to the optimization model. 


\section{Model Formulation}

An integer linear programming optimization model is formulated with the objective of maximizing profit through optimization of the product mix. The decision variable $\left(X_{r w o}^{t}\right)$ is the number of development wells (terminology used for wells drilled in the future) drilled during specified month (t), for specified category (rwo). Where " $r$ " is the reservoir that the well will be producing from; " $w$ " is the type of well whether it is vertical, deviated or horizontal; and "o" is the grade of crude oil whether it is light, medium or heavy depending on its API gravity. In this profit maximization model, revenue (R) and cost $(C)$ are the main components of the objective function as shown in Figure 1. Therefore, the objective function is defined as:

$$
\text { Maximize Profit }=\text { Revenue }(\mathrm{R})-\operatorname{Cost}(\mathrm{C})
$$

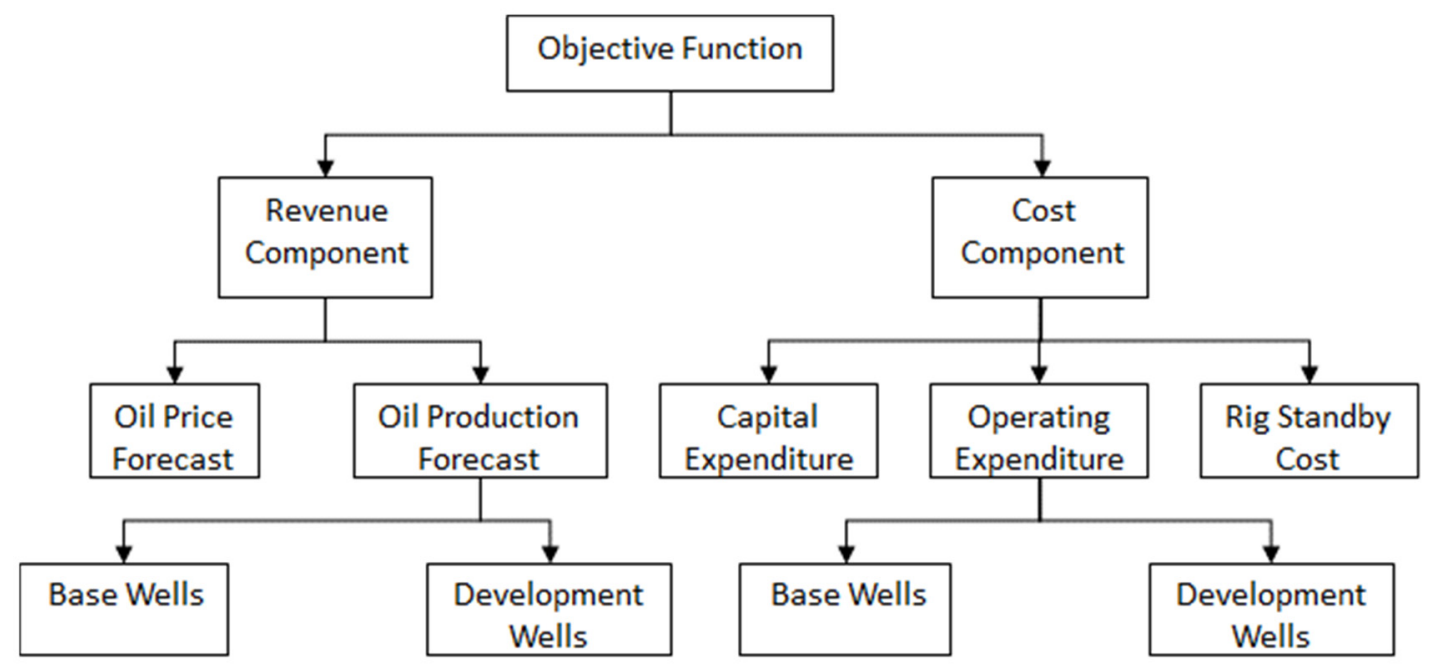

Figure 1. Components and subcomponents of the objective function

\subsection{Revenue Component}

Two sub-components are required; that is the oil price, and the amount of oil produced each month from both the base wells (terminology used for existing wells) and development wells.

\subsubsection{Oil Price Forecast}

The oil price is one of the most volatile elements of the model, it's not only affected by the supply and demand but also by the political situation that in many cases can't be predicted. There are deterministic and probabilistic models to predict the oil price, and their results show that the optimum production which achieves the maximum NPV is the same regardless of the model used. So, a deterministic model called "Floating Price model" is used because it is easy for implementation and less attributes are required compared to the probabilistic models. The model assumes that the crude prices are inelastic and grow with time regardless the effect of demand, it is given by (Bukhari and Jablonowski, 2012):

$$
P_{o}^{t}=P_{o}^{0} *\left(1+P_{o}^{g}\right)^{t}, \quad t=1,2, \ldots, t t ; o=1,2, \ldots, o o
$$

Where, tt is the planning period in months; oo is the total number of crude oil grades; $P_{o}^{0}$ is the current price of crude oil grade (o); and $\left(P_{o}^{g}\right)$ is the monthly price growth calculated using historical data for crude oil price as obtained from the US Energy Information Administration, 2014. The monthly data since January 2000 is plotted and the best fit shows the $\left(P_{o}^{g}\right)$ value of 0.009 USD as in Figure 2. 


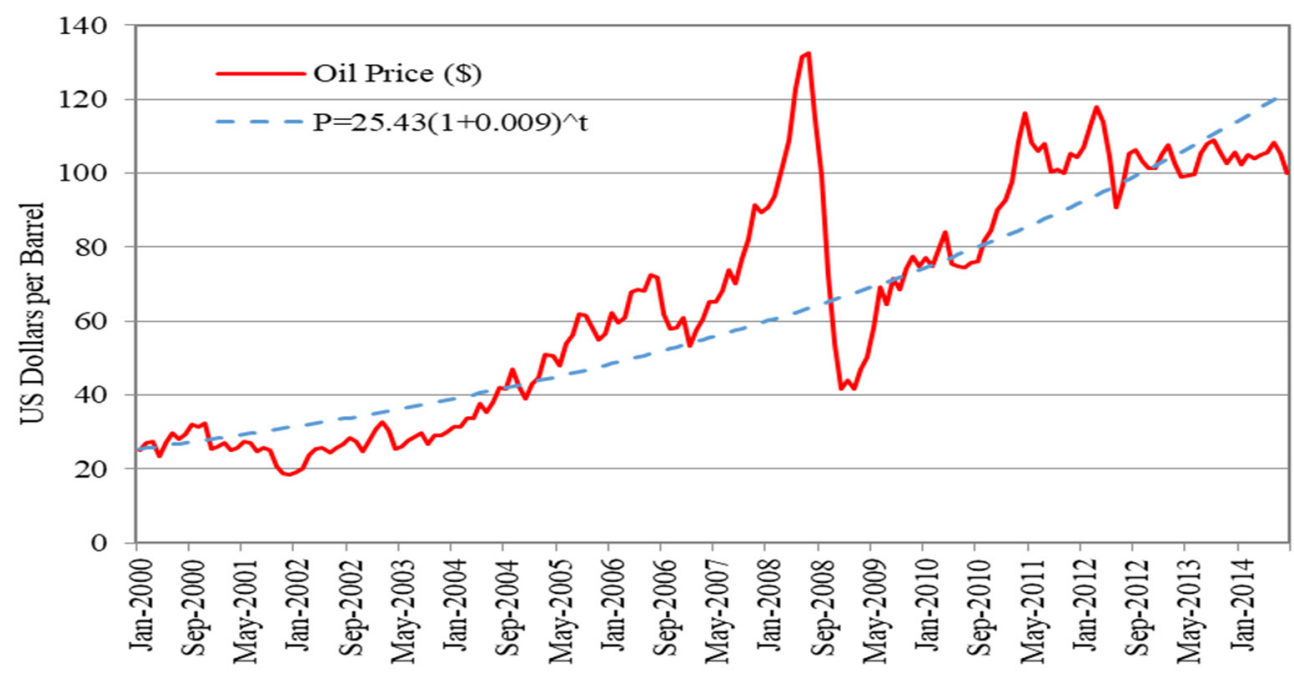

Figure 2. Crude oil monthly price - US dpllars per barrel

\subsubsection{Oil Production Forecast}

As per literature review, there are different methods used in estimating oil production forecast, and the simplest, most reliable and accurate method for a developed oil field is Decline Curve Analysis (DCA). Arps equations are applied to define three decline models: exponential; hyperbolic; and harmonic. Three parameters must be known to apply the model equations. Those parameters are initial production rate $\left(q_{r w o}^{0}\right)$, initial exponential decline rate $\left(D_{r w o}\right)$ and the degree of curvature or what is known as hyperbolic exponent $\left(b_{r w o}\right)$. The three Arps equations are (Bukhari and Jablonowski, 2012):

Exponential decline model $\left(b_{r w o}=0\right)$

$$
\begin{aligned}
& q_{r w o}^{t}=q_{r w o}^{0} \exp \left(-D_{r w o} *(t-1)\right), \\
& t=1,2, \ldots, t t ; r=1,2, \ldots, r r ; w=1,2, \ldots, w w ; o=1,2, \ldots, o o
\end{aligned}
$$

Hyperbolic decline model $\left(0<b_{\text {rwo }}<1\right)$

$$
\begin{aligned}
& q_{r w o}^{t}=\frac{q_{r w o}^{0}}{\left(1+b_{r w o} * D_{r w o} *(t-1)\right)^{1 / b_{r w o}}} \\
& t=1,2, \ldots, t t ; r=1,2, \ldots, r r ; w=1,2, \ldots, w w ; o=1,2, \ldots, o o
\end{aligned}
$$

Harmonic decline model $\left(b_{r w o}=1\right)$

$$
\begin{aligned}
& q_{r w o}^{t}=\frac{q_{r w o}^{0}}{\left(1+D_{r w o} *(t-1)\right)} \\
& t=1,2, \ldots, t t ; r=1,2, \ldots, r r ; w=1,2, \ldots, w w ; o=1,2, \ldots, o o
\end{aligned}
$$

Where, $q_{r w o}^{t}$ is the daily oil production in barrels of a single well produced from reservoir (r) of well type (w) and crude oil grade (o) during month (t).

On annual basis DCA is carried for all wells by using specialized software where each well is matched with one of the decline curves based on its historical production. Thus, the exponential decline rate $\left(D_{r w o}\right)$ and the hyperbolic exponent $\left(b_{r w o}\right)$ are obtained for each well. The first time daily oil production rate $\left(q_{r w o}^{0}\right)$ for similar wells of type (w) producing from reservoir (r) of crude oil grade (o) are averaged and fed into one of Arps Equations (3) - (5) to predict the future oil production rates.

The daily oil production forecast of all development wells produced from reservoir ( $\mathrm{r}$ ) of well type (w) and crude oil grade (o) during month $(\mathrm{t})$ in barrels $\left(Q_{r w o}^{t}\right)$ is calculated for the new wells drilled during this month as well as the ones drilled during the previous months, which have declined production rates, using the following equation:

$$
\begin{aligned}
& Q_{r w o}^{t}=\sum_{i=1}^{t} X_{r w o}^{i} * q_{r w o}^{t+1-i} \\
& t=1,2, \ldots, t t ; r=1,2, \ldots, r r ; w=1,2, \ldots, w w ; o=1,2, \ldots, o o
\end{aligned}
$$


The daily oil production of all developed wells in all reservoirs of oil grade (o) during month ( $\mathrm{t}$ ) in barrels is given by $\left(T Q O_{o}^{t}\right)$ :

$$
T Q O_{o}^{t}=\sum_{i=1}^{r r} \sum_{j=1}^{w w} Q_{i j o}^{t}, t=1,2, \ldots, t t ; o=1,2, \ldots, o o
$$

The forecast of the daily oil production of the base wells from reservoir (r) of crude oil grade (o) ( $\left.q b_{\text {ro }}^{t}\right)$ in barrels is calculated by applying Arps exponential decline model:

$$
q b_{\text {ro }}^{t}=q b_{\text {ro }}^{0} \exp \left(-D b_{\text {ro }} *(t-1)\right), t=1,2, \ldots, t t ; r=1,2, \ldots, r r ; o=1,2, \ldots, \text { oo }
$$

The model requires current production rate of base wells $\left(q b_{r o}^{0}\right)$ and their initial exponential decline rate $\left(D b_{r o}\right)$. The base wells oil production forecast of crude oil grade (o) during month $(\mathrm{t})$ in barrels $\left(T Q B O_{o}^{t}\right)$ is given by:

$$
T Q B O_{o}^{t}=\sum_{i=1}^{r r} q b_{i o}^{t}, t=1,2, \ldots, t t ; o=1,2, \ldots, o o
$$

Thus, the total daily revenue (R) in USD is given by the total oil produced per day from base wells and development wells during specific month multiplied by the oil price forecast of that month:

$$
R=\sum_{i=1}^{o o} \sum_{j=0}^{t t}\left(T Q O_{i}^{j}+T Q B O_{i}^{j}\right) * P_{i}^{j}
$$

\subsection{Cost component}

To calculate the cost component of the objective function, three sub-components are required these are the capital expenditure, the operating expenditure and finally the rig standby cost.

\subsubsection{Capital Expenditure (CAPEX)}

It is a one-time fixed cost paid initially at the time the well is drilled. CAPEX consists of three cost elements: drilling cost; completion cost; and site preparation cost. The following is the details of each.

The well drilling cost $\left(C_{\text {rwo }}^{D}\right)$ is given by:

$$
C_{r w o}^{D}=D D_{r w o} * R R, r=1,2, \ldots, r r ; w=1,2, \ldots, w w ; o=1,2, \ldots, o o
$$

Where, $\left(\mathrm{DD}_{\mathrm{rwo}}\right)$ is the number of days needed to drill a well of type $(\mathrm{w})$ in reservoir $(\mathrm{r})$, and $\mathrm{RR}$ is the daily drilling rate in USD.

The completion cost $\left(C_{\text {rwo }}^{C}\right)$ is the cost of preparing the well for operation and put it on production after the drilling is completed. Actual cost data from recently completed wells for each type of job is used to come-up with a cost catalog for each well type (w) drilled in a reservoir (r) of crude oil grade (o), in USD.

Site preparation and hook-up cost $\left(C^{S}\right)$ is the cost spent at the preparation stage prior to drilling the well, in addition to the hook-up cost spent for laying oil and gas lift pipelines from well manifold to the well location. Based on historical cost data an estimated single value of $C^{S}$ is provided for site preparation and hook-up cost in USD.

Thus, the Capital expenditure during month $(\mathrm{t})$ in $\operatorname{USD}\left(C A P E X^{t}\right)$ is:

$$
C A P E X^{t}=\sum_{i=1}^{r r} \sum_{j=1}^{w w} \sum_{k=1}^{o o} X_{i j k}^{t} *\left(C_{i j k}^{D}+C_{i j k}^{C}+C^{S}\right), t=1,2, \ldots, t t
$$

\subsubsection{Operating Expenditure during Month (t) $\left(O P E X^{t}\right)$}

It is obtained by adding the total oil produced from both base and development wells that are producing the same crude oil grade and multiplying the result by the operating cost of that crude oil grade (o) in USD / barrel $\left(C_{o}^{o}\right)$. It is given by:

$$
O P E X^{t}=\sum_{k=1}^{o o}\left(T Q O_{k}^{t}+T Q B O_{k}^{t}\right) * C_{k}^{o}, t=1,2, \ldots, t t
$$

Rig standby cost: The number of required rig days during month $(\mathrm{t})\left(R D R^{t}\right)$ is obtained by:

$$
R D R^{t}=\sum_{i=1}^{r r} \sum_{j=1}^{w w} \sum_{k=1}^{o o} X_{i j k}^{t} * D D_{i j k}, t=1,2, \ldots, t t
$$

Whereas the monthly average number of available rig days during month $(\mathrm{t})\left(R D A^{t}\right)$ is:

$$
R D A^{t}=\frac{\left(\left(N_{\text {Rigs }}^{T} * 365\right)-D_{F E}-D_{U P T}\right)}{12}, T=1,2, \ldots, T T ; \text { For all } t=(12 T-11),(12 T-10), \ldots, 12 T
$$

Where, $N_{\text {Rigs }}^{T}$ is the number of rigs during year T, $D_{U P T}$ is the number of unproductive days, and $D_{F E}$ is the number of days spent for formation evaluation.

Therefore, the rig standby cost during month $(\mathrm{t}),\left(\right.$ Rig_Cost $\left.^{t}\right)$, is obtained by:

$$
\text { Rig_Cost }{ }^{t}=\left(R D A^{t}-R D R^{t}\right) * R R, \quad t=1,2, \ldots, t t
$$

Where, RR is the drilling rig daily rate in USD. 
Thus, from Equations (12), (13) and (16), the total cost during month (t) $C M^{t}$ is:

$$
C M^{t}=\text { CAPEX } X^{t}+O P E X^{t}+\text { Rig_Cost }^{t}, t=1,2, \ldots, t t
$$

And the total cost $(\mathrm{C})$ over all months of the plan is:

$$
C=\sum_{i=1}^{t t}\left(C A P E X^{t}+O P E X^{t}+\text { Rig_Cost }^{t}\right)
$$

Therefore, the revenue Equation (10) and cost Equation (18) are fed into the objective function Equation (1) that to be solved for profit maximization.

\subsection{Constraints}

For this profit maximization problem seven inequality constraints are identified.

\subsubsection{Annual Budget Constraints}

It is important to keep the annual spending within the annual budgeted amount $\left(B^{T}\right)$. Thus:

$$
\sum_{i=(12 * T)-11}^{12 * T} C M^{i} \leq B^{T}, T=1,2, \ldots, T T
$$

Where, $\left(C M^{i}\right)$ is the total cost for month $\mathrm{i}$.

\subsubsection{Oil production Constraints}

The oil operating company should maintain the average daily oil production for specific year (T) $\left(T Q A^{T}\right)$ above the required minimum daily oil production for that year $\left(T Q T^{T}\right)$. Falling below this minimum requirement might result in paying penalties or compensation to the field owner. Thus:

$$
T Q A^{T}=\sum_{Z=(12 * T)-11}^{12 * T} \sum_{k=1}^{o o}\left(\left(T Q O_{k}^{Z}+T Q B O_{k}^{Z}\right) / 12\right) \geq T Q T^{T}, T=1,2, \ldots, T T
$$

\subsubsection{Facilities Constraints}

It is very important to understand the capability of the existing surface facilities in handling the base wells and development wells' oil, water and gas production rates. In addition to the oil production, the water production and gas production are also calculated for both base and development wells.

The water production forecast of a single development well in barrels/day produced from reservoir (r) of well type (w) and crude oil grade (o) drilled during month $(\mathrm{t})\left(w_{r w o}^{t}\right)$ is given by:

$$
w_{r w o}^{t}=q_{r w o}^{t} * W O R_{\text {rwo }}, \quad t=1,2, \ldots, t t
$$

Where, $W O R_{\text {rwo }}$ is the water oil ratio of a single development well.

Thus, water production forecast of all development wells $\left(W_{r w o}^{t}\right)$ is given by:

$$
W_{r w o}^{t}=\sum_{i=1}^{t} X_{r w o}^{i} * w_{r w o}^{t+1-i}, t=1,2, \ldots, t t ; r=1,2, \ldots, r r ; w=1,2, \ldots, w w ; o=1,2, \ldots, o o
$$

Similarly, water production forecast of base wells produced from reservoir (r) of crude oil grade (o) (WB $\left.B_{r o}^{t}\right)$ in barrels/day is given by:

$$
W B_{r o}^{t}=q b_{r o}^{t} * W O R B_{r o}, t=1,2, \ldots, t t
$$

Where, $\left(W O R B_{\text {ro }}\right)$ is the base wells water to oil ratio.

The daily gas production forecast of a single development well produced from reservoir ( $\mathrm{r}$ ) of well type (w) and crude oil grade (o) drilled during month (t) $\left(g_{r w o}^{t}\right)$ in thousand standard cubic feet per day (Mscf/d) is given by:

$$
g_{r w o}^{t}=q_{r w o}^{t} * G O R_{r w o}, t=1,2, \ldots, t t
$$

Where, $\left(G O R_{r w o}\right)$ is gas oil ratio of a development well.

Hence, the daily gas production forecast of all development wells $\left(G_{r w o}^{t}\right)$ in $(\mathrm{Mscf} / \mathrm{d})$ is given by:

$$
G_{r w o}^{t}=\sum_{i=1}^{t} X_{r w o}^{i} * g_{r w o}^{t+1-i}, t=1,2, \ldots, t t ; r=1,2, \ldots, r r ; w=1,2, \ldots, w w ; o=1,2, \ldots, o o
$$

Similarly, the daily gas production forecast of base wells produced from reservoir (r) of crude oil grade (o) $\left(G B_{\text {ro }}^{t}\right)$ is obtained by:

$$
G B_{r o}^{t}=q b_{r o}^{t} * G O R B_{r o}, t=1,2, \ldots, t t
$$

Where, $\left(G O R B_{\text {ro }}\right)$ is the gas to oil ratio of base wells.

Therefore, the daily liquid production (oil and water) form both base wells and development wells for any month should be less than the total capacities of the well liquid handling manifolds $\left(W M L_{z}\right)$ in barrels per day, i.e.:

$$
\sum_{i=1}^{r r} \sum_{j=1}^{w w} \sum_{k=1}^{o o}\left(Q_{i j k}^{t}+W_{i j k}^{t}\right)+\sum_{i=1}^{r r} \sum_{k=1}^{o o}\left(q b_{i k}^{t}+W B_{i k}^{t}\right) \leq \sum_{z=1}^{N W M} W M L_{z}, t=1,2, \ldots, t t
$$


Where, $(N W M)$ is the number of well manifolds.

Similarly, the daily gas production from both base wells and development wells for any month should be less than the total capacities of the well gas handling manifolds $\left(W M G_{z}\right)$ in $(\mathrm{Mscf} / \mathrm{d})$, i.e.:

$$
\sum_{i=1}^{r r} \sum_{j=1}^{w W} \sum_{k=1}^{o o} G_{i j k}^{t}+\sum_{i=1}^{r r} \sum_{k=1}^{o o} G B_{i k}^{t} \leq \sum_{z=1}^{N W M} W M G_{z}, t=1,2, \ldots, t t
$$

3.3.4 Reserve Constraints

The amount of oil produced from base and development wells should not exceed the available recoverable amounts. This can be achieved by calculating the amount of oil expected to be produced from both base and development wells and the remaining recoverable amount of oil that can be produced.

The amount of oil that is expected to be produced form reservoir $(\mathrm{r})$ of oil grade (o) $\left(E O R_{r o}\right)$ in barrels is calculated by:

$$
E O R_{r o}=\frac{365}{12} * \sum_{i=1}^{t t} \sum_{j=1}^{w w}\left(Q_{r j o}^{i}+q b_{r o}^{i}\right), r=1,2, \ldots, r r ; o=1,2, \ldots, o o
$$

The oil reserve $\left(R O R_{r o}\right)$ is the recoverable amount of oil that can be produced from the Original Oil In Place $\left(O O I P_{r o}\right)$ in barrels, and it is established by:

$$
R O R_{r o}=\left(O O I P_{r o} * R F_{r o}\right)-Q P_{r o}, r=1,2, \ldots, r r ; o=1,2, \ldots, o o
$$

Where, $R F_{r o}$ is a recovery factor, $Q P_{r o}$ is cumulative oil that already being produced from reserve available.

Thus, the reserve constraints are:

$$
R O R_{r o} \geq E O R_{r o}, r=1,2, \ldots, r r ; o=1,2, \ldots, o o
$$

\subsubsection{Number of Drilling Rigs Constraints}

The number of rig days available during month $(\mathrm{t})\left(R D A^{t}\right)$ should be equal or greater than the number of rig days required during the specific month $\left(R D R^{t}\right)$. Thus, the drilling rig constraints are:

$$
R D R^{t} \leq R D A^{t}, t=1,2, \ldots, t t
$$

\subsubsection{Maximum Number of Wells Constraints}

These constraints have been introduced to avoid interference in production between wells, and to guarantee that the model have an upper limit for each decision variable to avoid infinite and unrealistic number of decision variables. Thus, the maximum number of wells constraints are:

$$
\sum_{i=1}^{t t} X_{r w o}^{i} \leq N_{r w o}, r=1,2, \ldots, r r ; w=1,2, \ldots, w w ; o=1,2, \ldots o o
$$

Where, $N_{r w o}$ is the maximum number of wells to be drilled from reservoir (r) of well type (w) of crude oil grade (o).

\subsubsection{Integer Decision Variables Constraints}

Since a portion of a well cannot be drilled, all decision variables need to be integer as the following:

$$
\text { All } X_{r w o}^{t} \text { are integers }, t=1,2, \ldots, t t ; r=1,2, \ldots, r r ; w=1,2, \ldots, w w ; o=1,2, \ldots, o o
$$

\section{Model Solution Using MATLAB}

Since all formulated equations are linear, and the decision variables are constrained to be integers, therefore the most suitable optimization model for solving the problem is an integer liner optimization model. Mixed-integer linear program (MILP) function "intlinprog" of MATLAB software is used to solve the model. The "intlinprog" function minimizes the objective function using the optimization options and the given constraints.

The equations formulated are re-arranged to be suitable for MATLAB. This is done by arranging the objective function and constraints coefficients in matrix and vector formats. As shown in Figure 3, the Main Module in MATLAB calls 16 sub-modules in sequence. This structure helps in future updates and enhancement of the model. The optimization results obtained by the output sub-module are used to generate fluid streams, revenue, cost and profit which are based on the decision variables' results. The output sub-module creates the report header and contents and exports it to Excel spreadsheet. 


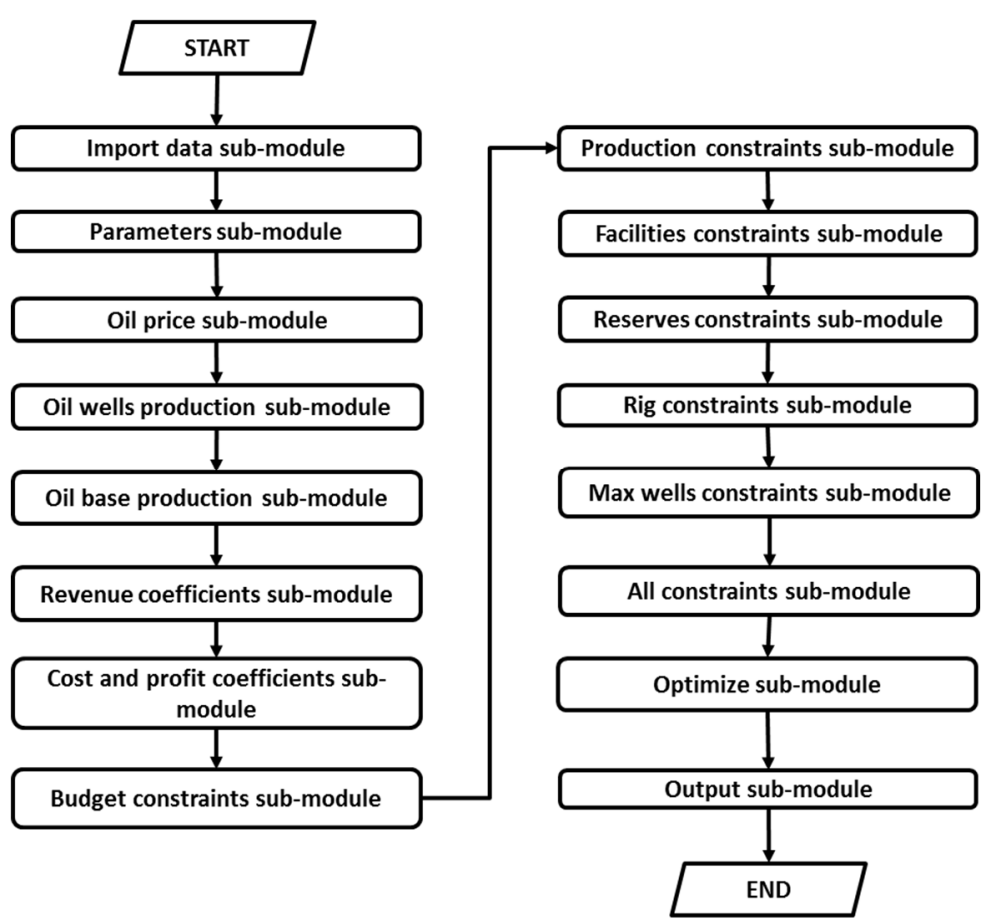

Figure 3. MATLAB main-module

\section{Model Validation}

The validation process is carried out by testing different sets of data in MATLAB and Excel spreadsheet model and comparing the results. Microsoft Excel built-in SOLVER tool is used. However, SOLVER has limitations, it can only handle up to 200 decision variables and 100 constraints' cells. In addition, SOLVER can only solve problems created in a single sheet which limits the range of data sets to be used.

An Excel model is developed that consists of four parts, part one is for the input parameters. In part two, computations are made for oil price forecast, wells oil production forecast, base wells' oil, gas and water forecast, and remaining facilities handling capacities. In part three, the initial values for the decision variables are entered, and based on these values the objective function is calculated. In part four, the seven constraints are automatically computed in excel. Once all parts are arranged and inputs are entered, the SOLVER analysis tool is run.

Different combinations of parameters and constraints are used for creating ten validation examples. The examples are categorized into three categories considering the number of reservoirs, number of well types, number of crude oil grades and number of decision variables as summarized in Table (1). A combination of the number of reservoirs, number of well types, and number of crude oil grades are referred to as a Reference (Ref). Other parameters such as oil price, budget, facilities handling capacity, number of rigs and cost are also changed from one example to another.

Table 1. Categories of model validation examples

\begin{tabular}{|c|c|c|c|c|c|c|}
\hline \multirow{2}{*}{$\begin{array}{l}\text { Category } \\
\text { Number }\end{array}$} & \multirow{2}{*}{$\begin{array}{l}\text { Example } \\
\text { Number }\end{array}$} & \multicolumn{5}{|c|}{ Number of: } \\
\hline & & Reservoirs & Well types & Crude oil grade & Ref. & Decision variables \\
\hline 1 & $1,2,3,4$ & 1 & 1 & 1 & 1 & 24 \\
\hline \multirow[t]{2}{*}{2} & 5,6 & 1 & 2 & 1 & 2 & 48 \\
\hline & 7 & 2 & 2 & 2 & 2 & 48 \\
\hline \multirow[t]{2}{*}{3} & 8,9 & 2 & 3 & 1 & 4 & 96 \\
\hline & 10 & 2 & 3 & 2 & 3 & 72 \\
\hline
\end{tabular}

The parameters for each example are entered in the spreadsheet model and MATLAB model, and the optimization results are obtained and compared. After running the ten validation examples, it is found that both Excel spreadsheet model and MATLAB model provide exactly matched optimum results with the same number of development wells and same monthly distribution of these wells over two years planning period, as well as the same value of the objective function (profit). In addition, the monthly oil production rates, and the monthly cash 
flow of revenue, cost and profit generated by the two models are the same. A summary of the results from the ten examples are graphically illustrated in Figures 4 and 5.

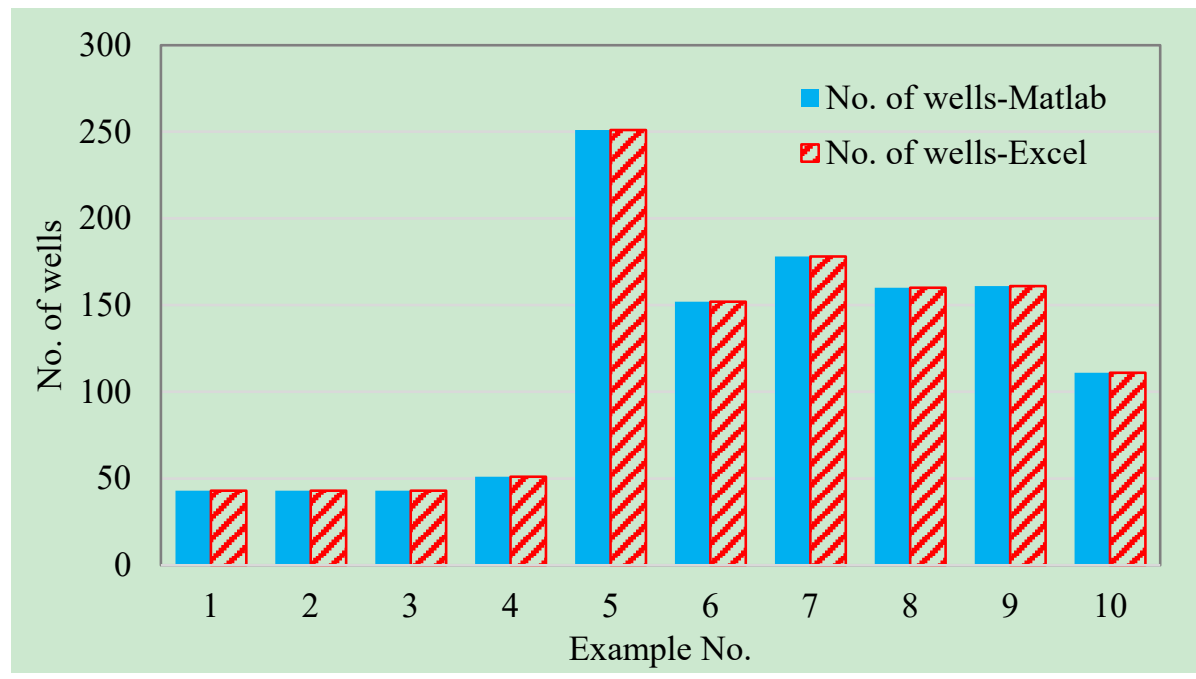

Figure 4. Model validation examples: Number of wells

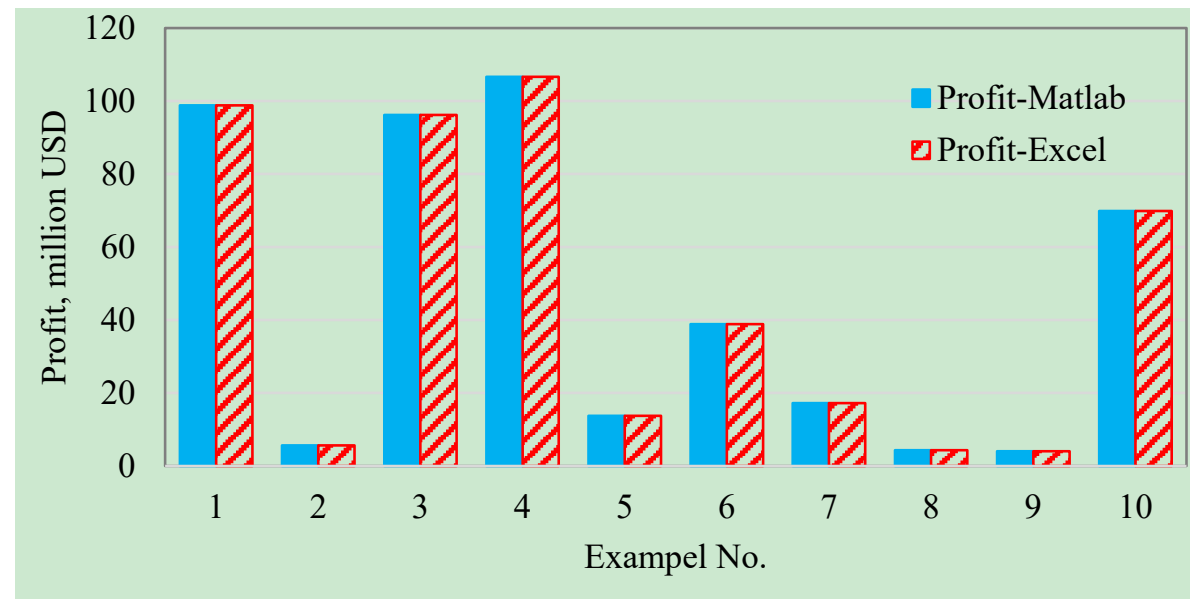

Figure 5. Model validation examples: Objective function

\section{Model Application for Solving Real Case Problems}

Annually oil field operating companies prepare their five-year plan where the strategies and budget needed for developing the field and reservoirs are included. One of the main strategies is planning the number of development wells to be drilled in the next five years with the oil production forecast associated with it. The selection of well mix in the plan is mainly based on maximizing production instead of profit. Although it sounds that maximizing production will lead to maximizing profit but this is not always true. In order to measure the benefits of using this research optimization model, real data sets are used. Three sets of data for plans of three consecutive years, each of five years period, are used. The data coverage is summarized in Table (2).

Table 2. Three years data sets summary

\begin{tabular}{ccccccc}
\hline Year & \multicolumn{5}{c}{ Number of: } \\
\cline { 2 - 7 } & Reservoirs & Well types & Crude oil grade & Ref. & Decision variables & Constraints \\
A & 9 & 4 & 2 & 19 & 1140 & 3620 \\
B & 9 & 5 & 2 & 36 & 2160 & 6680 \\
C & 9 & 5 & 2 & 56 & 3360 & 10280 \\
\hline
\end{tabular}

The model is run for the three years plans. The model output is referred to as optimized plan, and the company prepared plan is referred to as original plan. In the following paragraphs the MATLAB optimized plan for year C 
and the corresponding original plan are compared and discussed, then a summarized comparison of the three years plans is presented.

Decision variables: The optimized results recommend to drill 238 wells from 25 well references compared to 926 wells from all 56 well references in the original plan, i.e. about $74 \%$ reduction in the number of wells to be drilled. Both optimized and original plans suggest to drill the same number of wells for 24 references, and they suggest to drill different number of wells for one reference. On the other hand, the optimized plan recommends not to drill any well from the remaining 31 well references, while the original plan recommends to drill around 700 wells from these remaining references, where only two of them are used to drill 500 wells.

The original plan schedule recommends continuous drilling for 5 years with uniform number of wells for each year, where in the first two years it averages 12 wells per month from different well references, and around 24 wells per month mainly from two specific references for the remaining years as illustrated in Figure 6 . The optimized plan recommends to drill the majority of the wells in different batches at different timings. The first batch consists of around 60 wells to be drilled in the first four months mainly from specific reference, while the second batch consists of over 50 wells to be drilled from month 10 to 14 mainly from another specific reference. The third batch proposes to drill over 150 wells, more than $50 \%$ from one reference during the period from 28 to 36 months. The final batch recommends to drill over 80 wells from different well references at the end of the fourth year and beginning of fifth year as illustrated in Figure 7.

Oil production: Oil production forecast rates from base wells is the same for both plans. In both plans, the production starts at 51600 and declines to around 15200 barrels/day by the end of year 5 . Whereas for development wells, it is proportionally related to the number of wells being drilled. Therefore, the original plan shows a continuous increase in oil production rate from 900 to 52500 barrels/day due to the continuous drilling activities. It is noticed that oil production rate is higher in the last three years due to more wells are planned in those years. On the other hand, the optimized plan proposes wells to be drilled in mainly four batches, therefore the oil production rate increases with every drilling batch, then declines afterwards. Thus, for the development wells the oil production rate reaches its maximum of 33800 barrels/day at month 49 and declines to 25400 barrels/day by the end of the fifth year.

The total oil production is plotted for both plans in Figure 8, where the original plan shows a higher oil production rate than the optimized plan for the entire period with the exception of the first five months. The gap between both plans increases with time and reaches to 26700 barrels/day by the end of the planning period. The total oil production by the end of the five years is 67700 and 40600 barrels/day for the original and optimized plans, respectively.

Revenue: Revenue from base wells is the same for both plans, it starts at $\$ 5.2$ million and declines to around $\$ 2.6$ million by the end of fifth year with a total revenue of \$224 million for the planning period. For development wells, the original plan shows continuous increase in revenue from $\$ 0.1$ million to $\$ 9$ million with continuous increase of oil production and oil price. Whereas for the optimized plan, the revenue increases from $\$ 0.13$ million to $\$ 4.3$ million showing sudden increases with the increase of oil production associated with each drilling batch. The total revenue of the development wells from original and optimized plans are \$232 million and \$156 million, respectively.

The total revenue is plotted for both plans in Figure 9, where the original plan shows a higher revenue than the optimized plan for the entire period with the exception of the first five months. The gap between both plans increases with time and reaches to $\$ 7.7$ million by the end of the planning period. The total revenue from the original and optimized plans are $\$ 456$ million and $\$ 380$ million, respectively.

Cost: The operating cost of base wells is the same for both plans and it is almost negligible compared to the capital and overall cost. It starts with $\$ 0.62$ million and declines to around $\$ 0.18$ million by the end of fifth year with a total cost of $\$ 21.5$ million for the planning period.

About ninety eight percent of development wells cost is related to the capital cost and rig standby cost, and the remaining is related to the operating cost. The total operating cost for the original plan is $\$ 23.5$ million versus $\$ 13.1$ million for the optimized plan (44\% reduction). The capital cost depends on the number of wells to be drilled, therefore the original plan have continuous capital spending due to the continuous drilling, resulting into a total capital cost of $\$ 1342$ million. On the other hand, the optimized plan capital cost is focused on specific periods associated with drilling batches. The total capital cost of the latter plan is $\$ 359$ million with more than $73 \%$ reduction compared to original plan cost. Since the original plan have a continuous drilling versus an intermittent drilling by the optimized plan, therefore the rig standby cost for original plan is lower at $\$ 151$ million than the optimized plan at $\$ 617$ million ( $300 \%$ higher cost). 
The total cost is shown in Figure 10 for both plans, the optimized plan shows a higher cost by $\$ 2$ million in the first four months from the original plan. For the remaining months the original plan shows a higher cost with the exception when the optimized plan recommends to drill, the costs of both plans are nearly the same. The total cost for the original and optimized plans are \$1538 million and \$1011 million, respectively, where original plans has a higher total cost of $\$ 527$ million (34\% cost reduction for optimized plan).

Profit: The profit has a negative cash flow (i.e. loss) as illustrated in Figure 11. The conclusion is that profit is driven by drilling capital cost for the original plan and rig standby cost for the optimized plan. The loss with the original plan ranges between ( $\$ 5.7$ million) to (\$29.4 million), and it ranges between ( $\$ 2.3$ million) to (\$29.1 million) with the optimized plan

The cumulative profit presented in Figure 12 shows the total profit versus time. By the end of the planning period, the original plan has a loss of (\$1082 million) and the optimized plan has a loss of (\$631 million). Which means that the optimized plan has $42 \%$ less loss than the original plan.

The actual data used in this study is obtained from a company which did not breakeven yet, therefore all the benefits and savings reflected in the results produced from the optimization model is described as minimizing losses rather than maximizing the profit. Running the optimization model using the actual data for plans of three consecutive years, each of five years period, has shown that:

- $\quad$ For the three plans, both original and optimized plans do not show breakeven point within the five years planning period and need to extend for longer periods to start getting profit.

- $\quad$ The optimized plans provide less losses than the original plans for the three plans as illustrated in Figure 13. An average cost saving of around $\$ 471$ million can be achieved for each plan with cost saving ranging between $42 \%$ and $47 \%$.

The plans have the potential for further improvements by optimizing number of rigs, while at the same time meeting the oil production target through the product mix.

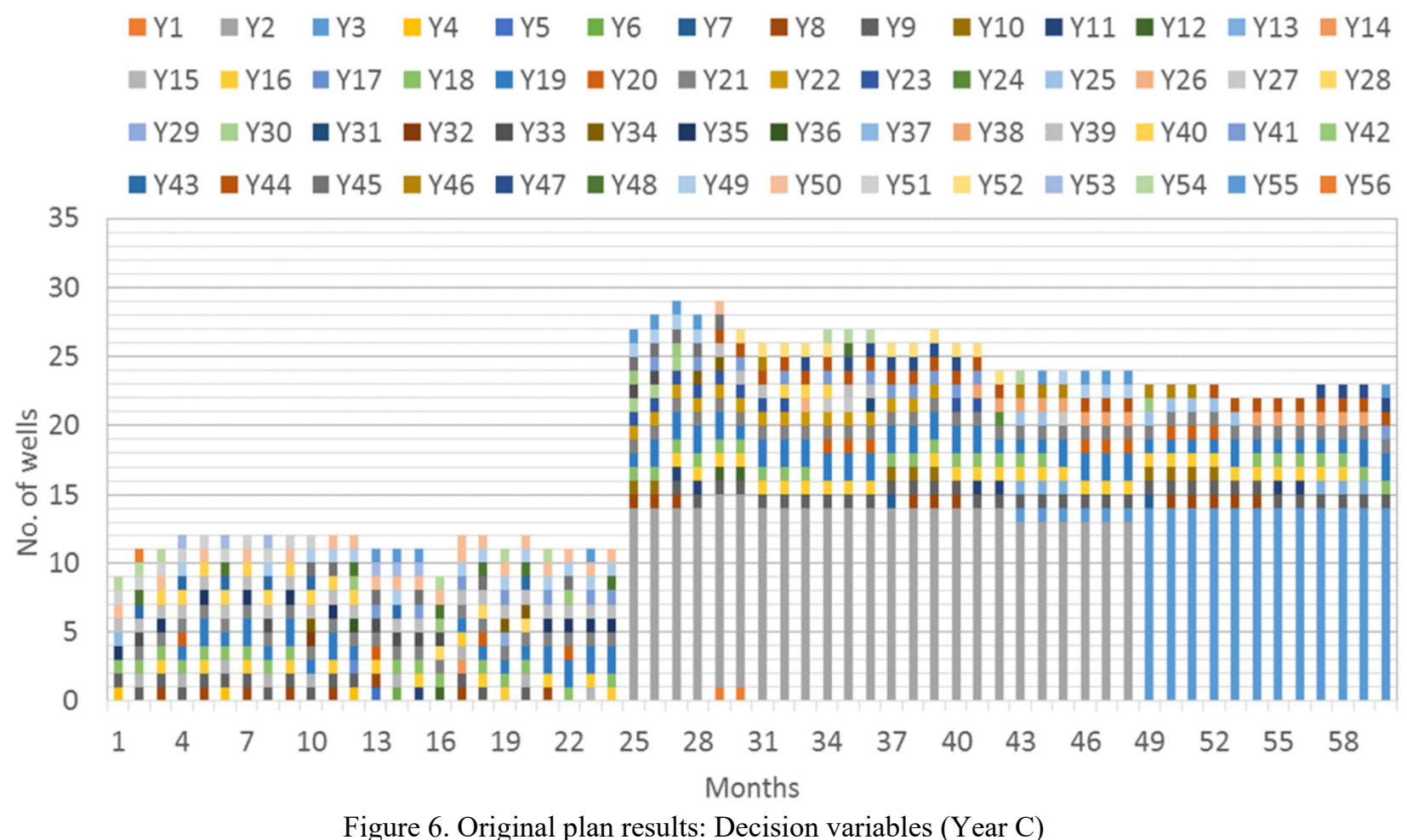

Figure 6. Original plan results: Decision variables (Year C) 


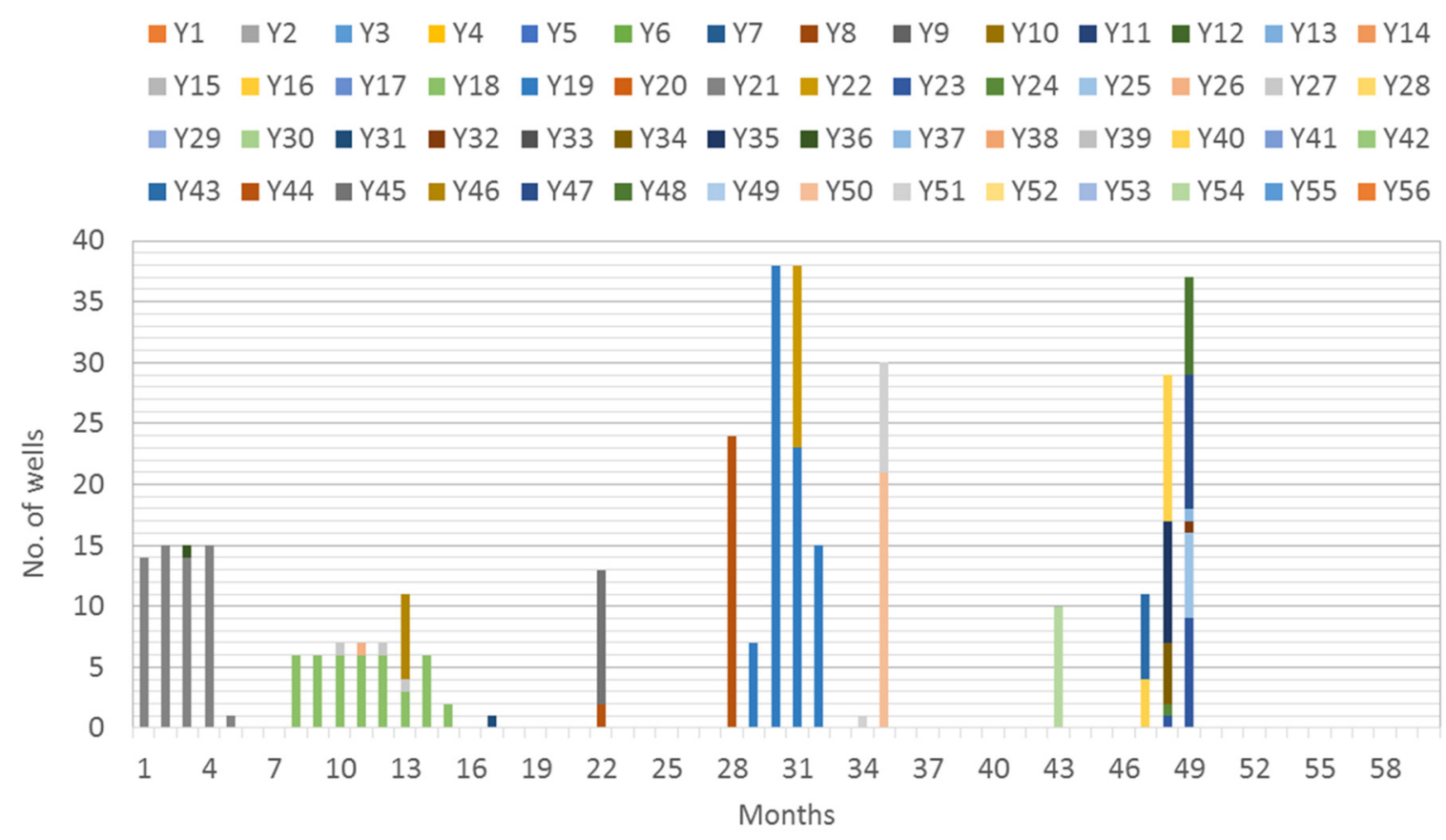

Figure 7. Optimized plan results: Decision variables (Year C)

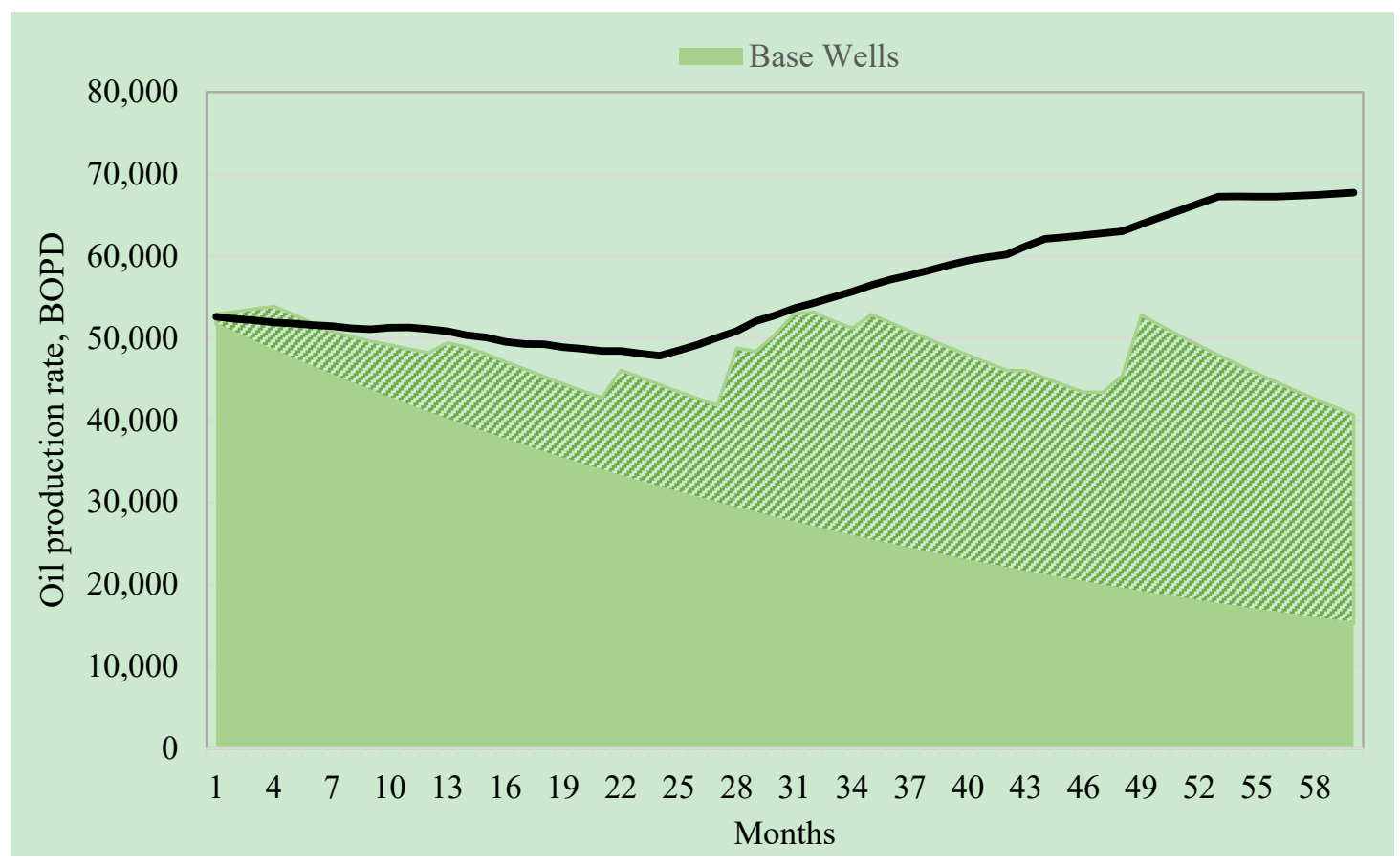

Figure 8. Optimized vs original results: Oil production (Year C) 


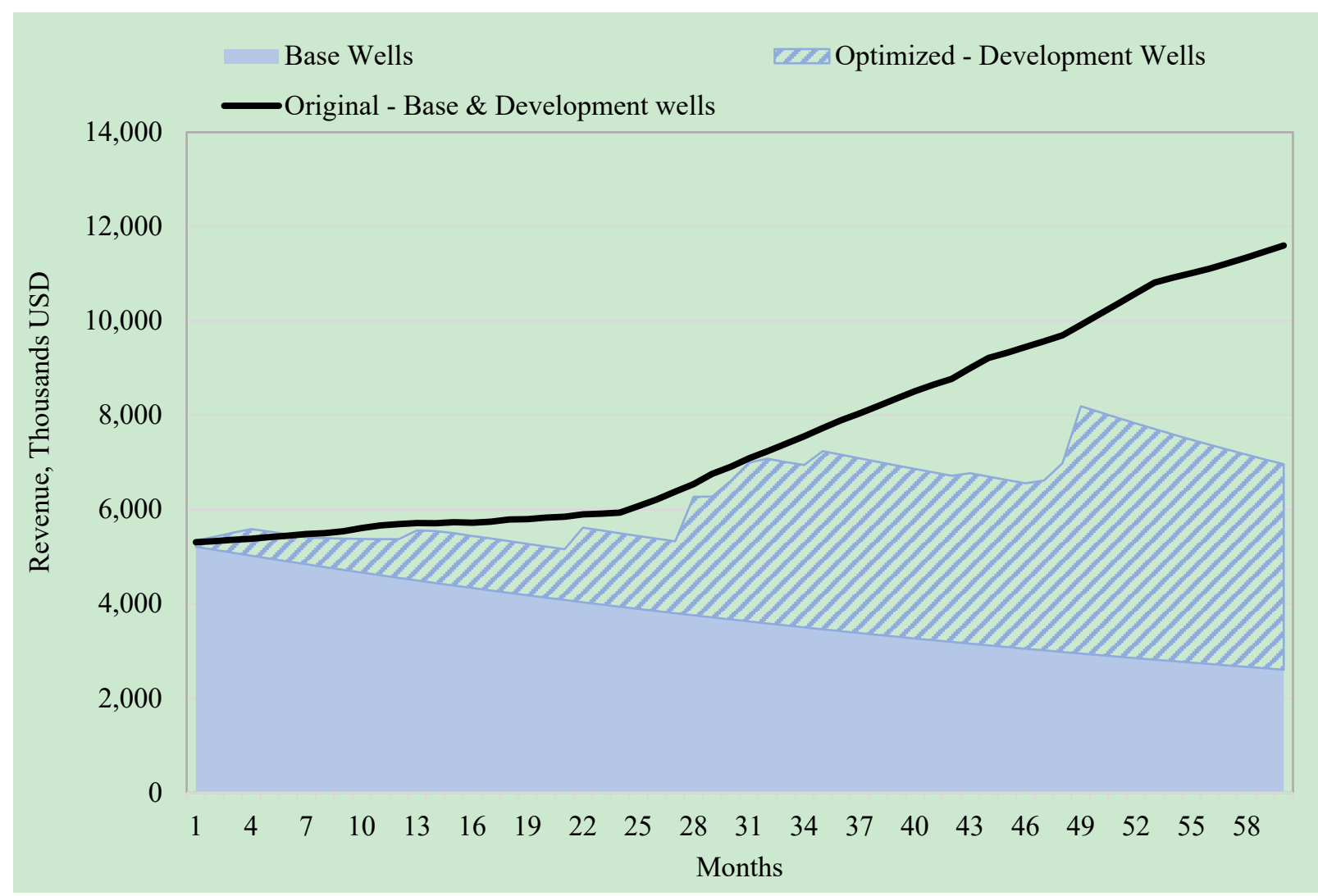

Figure 9. Optimized vs original results: Revenue (Year C)

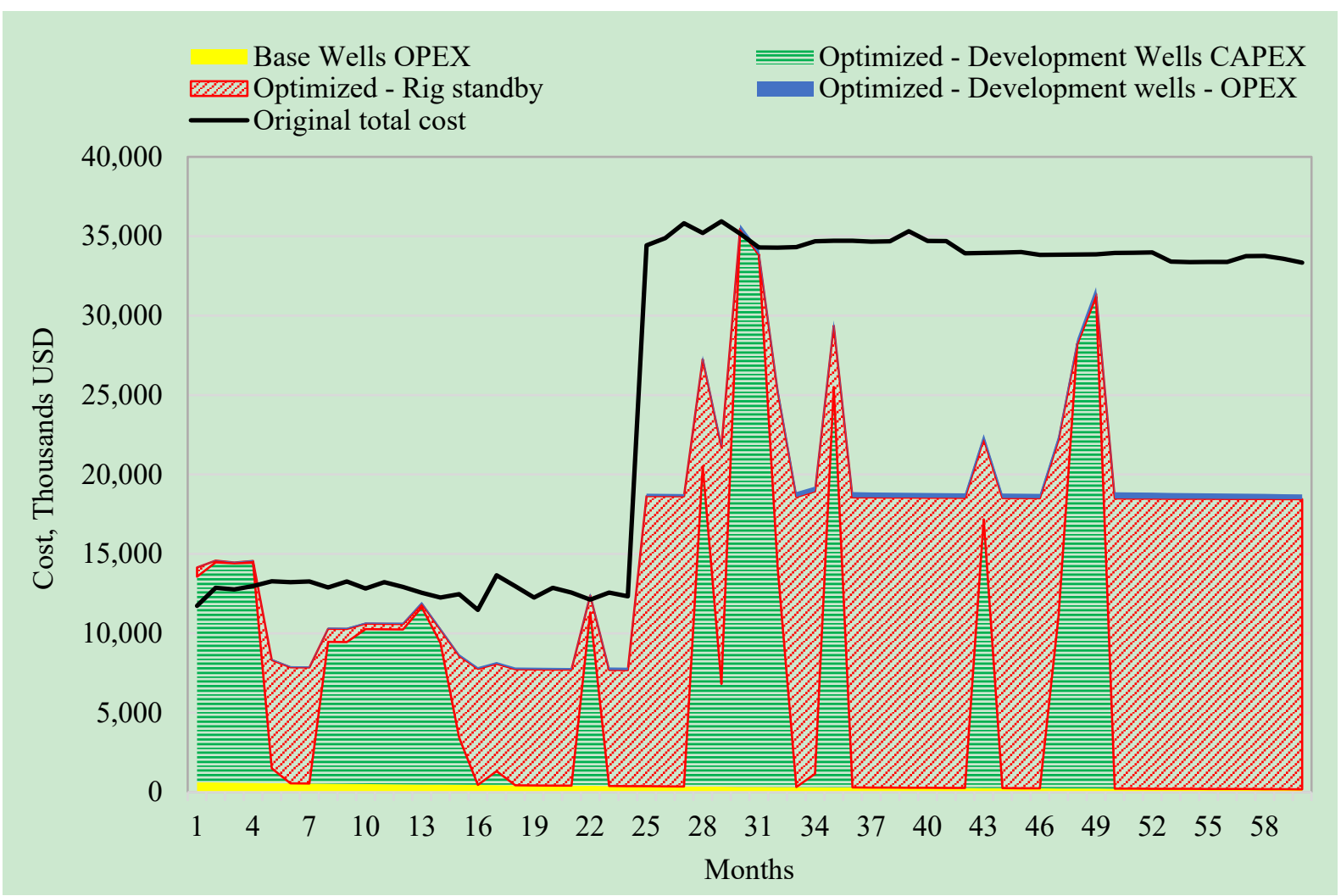

Figure 10. Optimized vs original results: Cost (Year C) 


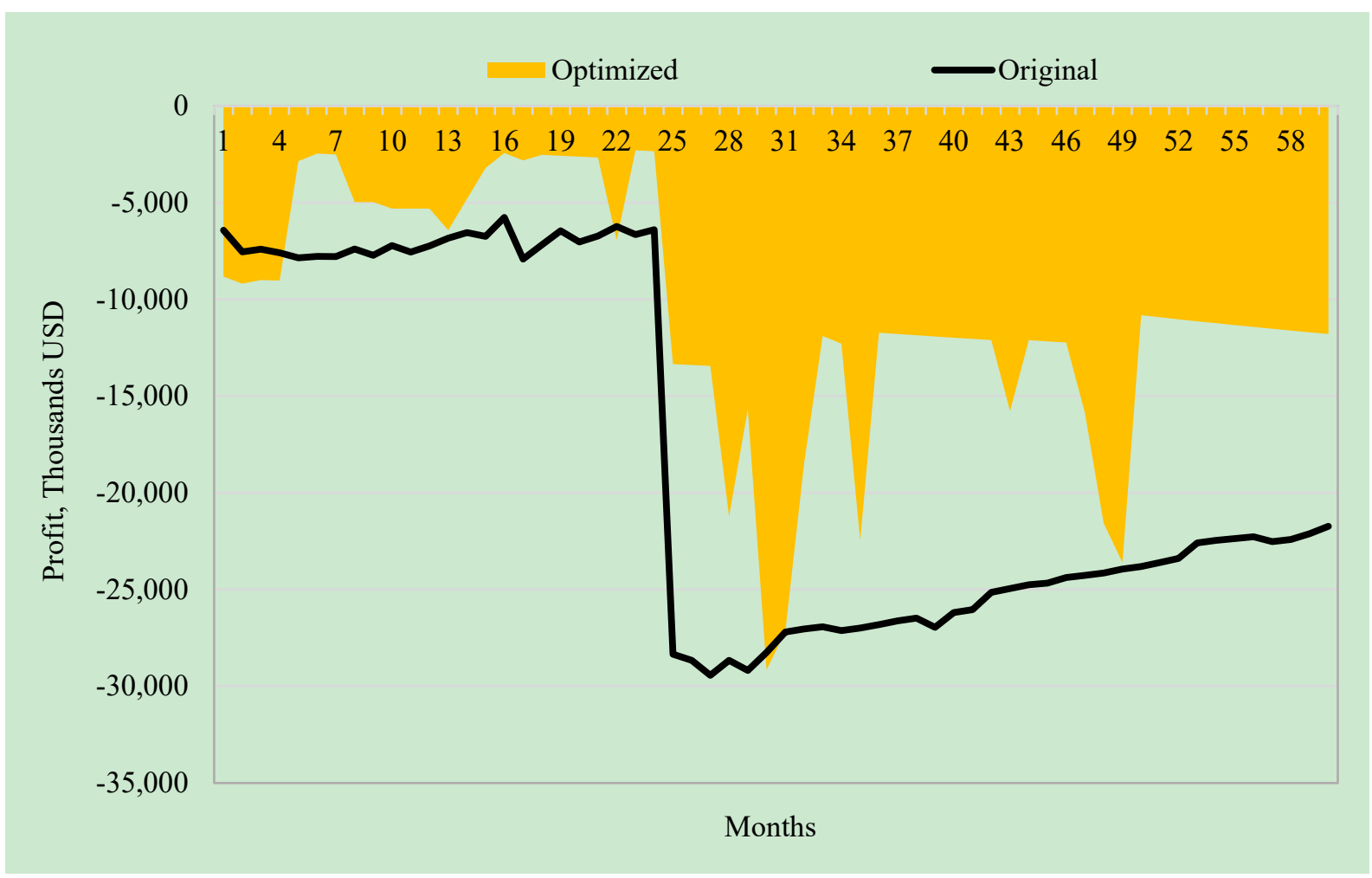

Figure 11. Optimized vs original results: Profit (Year C)

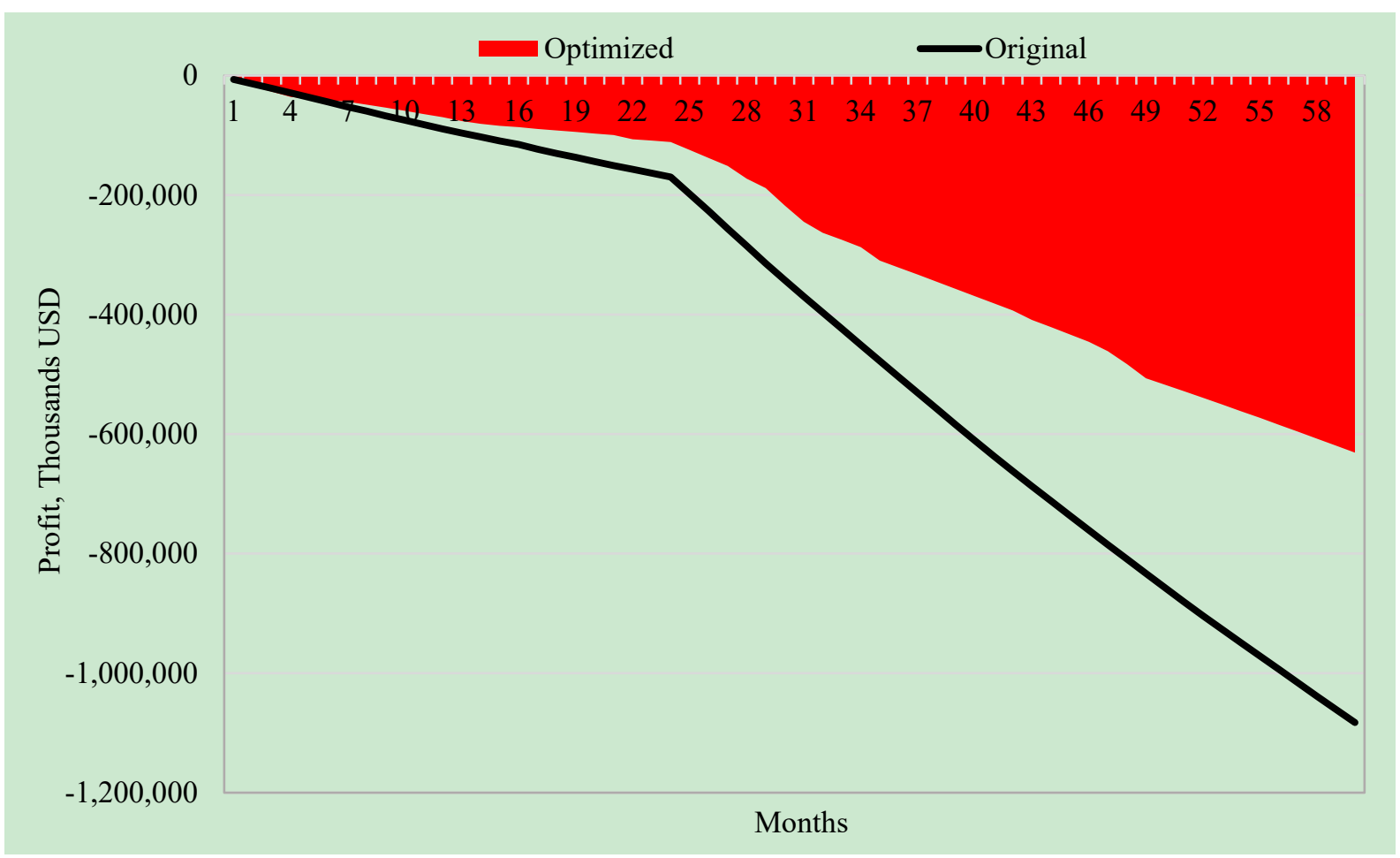

Figure 12. Optimized vs original results: Cumulative profit (Year C) 


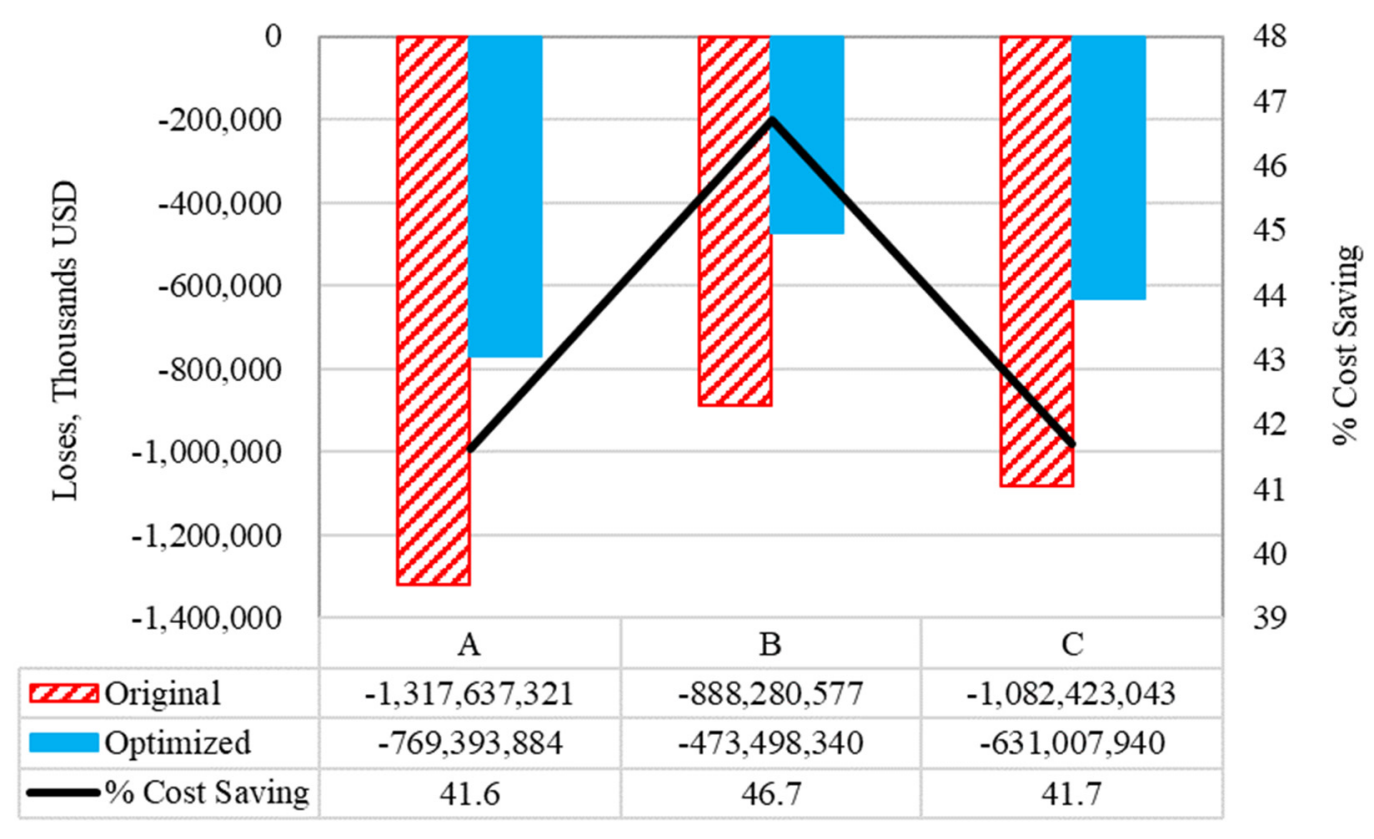

Figure 13. Optimized vs original profit difference summary

\section{Sensitivity Analysis}

Sensitivity analysis started with eliminating all parameters related to reservoir characteristics and well performance since those are either facts or data that need extensive studies. The second step is to focus on factors affecting the profit (revenue and cost), this includes oil price, rig daily cost, completion cost, site preparation and hook-up cost, budget, minimum oil production rates, number of rigs and facilities handling capacities. The model is run for Year $\mathrm{C}$ data set where each factor identified is increased or decreased by $+/-10 \%$ in each step and up to $+/-50 \%$, whereas the other parameters are set constant. Figure 14 presents the results obtained from running each case.

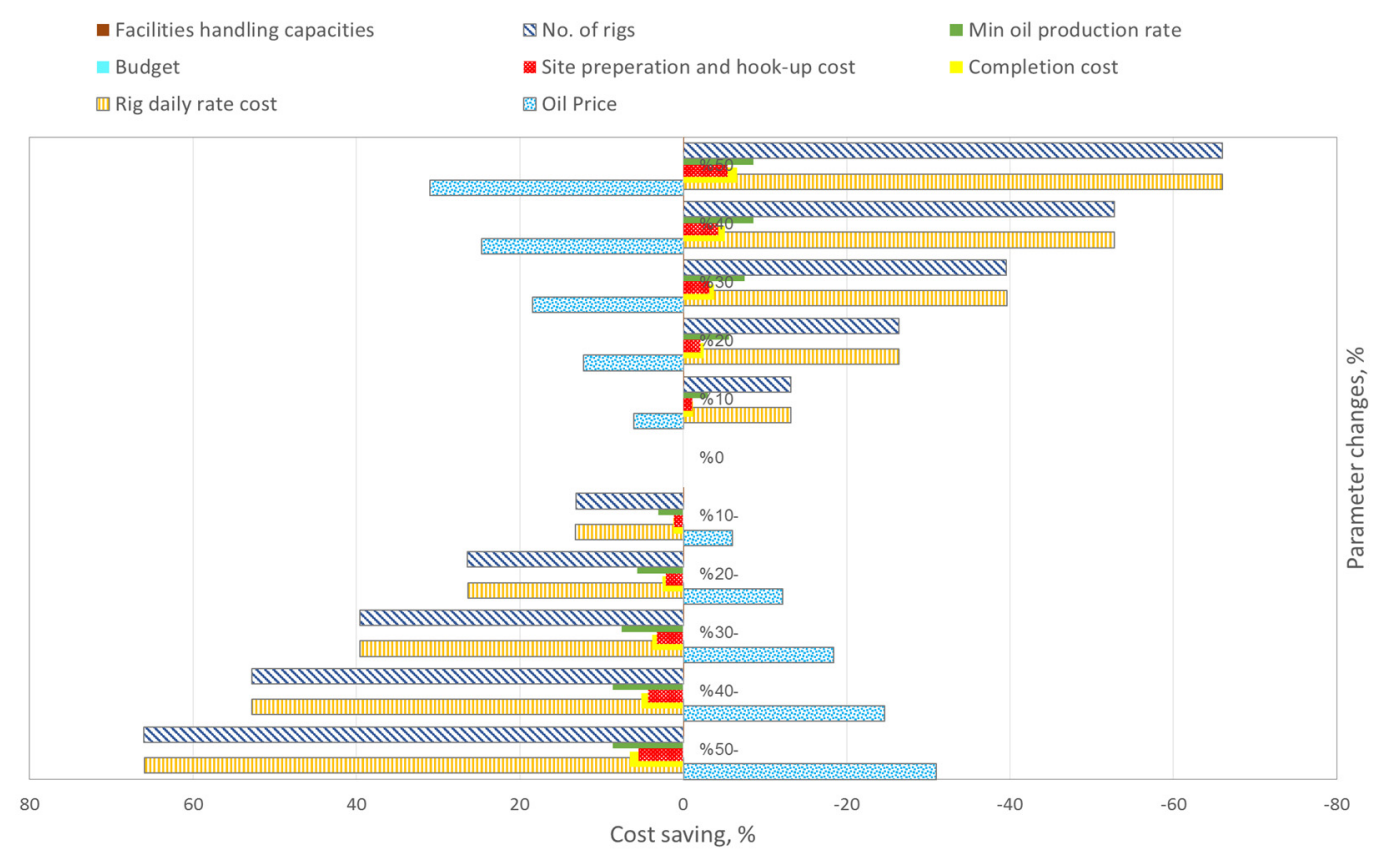

Figure 14. Sensitivity analysis results 
It is found that budget and facilities handling capacities have no impact on the profit, whereas completion cost, site preparation and hook-up cost and minimum production target have minor impact on profit. On the other hand, oil price have a good impact on profit, the analysis shows that with every $10 \%$ increase in oil price, the profit increases by about $6 \%$, thus profit is $33 \%$ higher with $50 \%$ increase in oil price. Also, the number of rigs and rig daily cost rate affect the profit tremendously, where by reducing these two parameters by $50 \%$ an increase of $66 \%$ in profit can be achieved.

\section{Conclusion}

Using the appropriate optimization methods is an effective way for solving many problems in the oil industry such as optimizing oil production and wells' drilling schedule. An integer linear mathematical programing model is formulated for solving the problem of maximizing profit by optimizing the oil production through optimum wells' mix. The model is solved by using MATLAB. Furthermore, an Excel model is formulated for small sized product mix problem for validation purpose. It is confirmed that the MATLAB model is valid, reliable and can be used for large sized real problems. Running the optimized model with data of real case has shown the advantages over the manual optimization approach used currently. The model optimized plans provide better performance than the tested original plans by showing an average cost saving of around $\$ 471$ million (47\%) for each plan. Furthermore, the analysis shows that with every $10 \%$ increase in oil price, the profit increases by about $6 \%$. Also, it shows that the number of rigs and the rig daily cost affect the profit tremendously, where by reducing these two parameters by $50 \%$ an increase of $66 \%$ in oil profit can be achieved. Thus, it is concluded that the number of rigs, daily rig rate and oil price are the major parameters that affect the profit, and any minor enhancement in any of these three parameters can affect the profit tremendously.

Two recommendations are suggested for future studies: first, to develop multi-objective optimization model that consider in addition to wells scheduling, wells surface locations; and second, to modify the model to consider the net present value (NPV) of money, this will change the model from integer linear to integer nonlinear optimization model.

\section{References}

Arnondin, M. C. (1995). Integration of production analyst and Microsoft Excel's Solver for production forecasts and optimization. SPE Computer Applications, 7(5). https://doi.org/10.2118/27566-PA

Aronofsky, J. S. (1983). Optimization methods in oil and gas development. Journal of Petroleum Technology.

Atnagulov, A. R., Ismagilov, R. R., Nekipelov, Y. V., \& Kireev, G. A. (2010). Optimization methods of profitability assessment and well cluster drilling rating with account of capital expenditure. SPE paper 136153. Presented at the 2010 SPE Russian Oil and Gas Technical Conference and Exhibition, Moscow, Russia, 26-28 October. https://doi.org/10.2118/136153-MS

Behmiri, N. B., \& Manso, J. R. P. (2011). Crude oil price forecasting techniques: a comprehensive review of literature. Alternative Investment Analyst Review. https://dx.doi.org/10.2139/ssrn.2275428

Bukhari, A. A., \& Jablonowski, C. J. (2012). Optimization of production allocation underprice uncertainty: relating price model assumptions to decisions. SPE paper 151673. Presented at the SPE Latin Americal and Caribian Petroleum Engineering Conference, Mexico City, Mexico, 16-18 April 2012. https://doi.org/10.2118/151673-MS

Darwis, S., Ruchjana, B. N., \& Permadi, A. K. (2009). Robust decline curve analysis. Journal of Indonesia Mathematical Society, 15(2), 105-111. https://doi.org/10.22342/jims.15.2.50.105-111

Gabralla, L. A., \& Abraham, A. (2013). Computational modeling of crude oil price forecasting: A review of two decades of research. International Journal of Computer Information System and Industrial Management Applications, 5, 729-740.

Huang, N. S., Frankel, D. S., \& Noman, A. M. (2012). Integrated modelling to optimize field development of a giant field. SPE paper 161987. Presented at Abu Dhabi International Petroleum Exhibition and Conference, Abu Dhabi, UAE, 11-14 November. https://doi.org/10.2118/161987-MS

Irgens, M., \& Lavenue, W. L. (2007). Use of advanced optimization techniques to manage a complex drilling schedule. SPE paper 110805. Presented at the 2007 SPE Annual Technical Conference and Exhibition, California, USA, 11-14 November 2007. https://doi.org/10.2118/110805-MS

Irgens, M., Guzman, R. P., Stamatopoulos, J., \& Jackson, K. (2007). Optimization for operational decision support: The rig fleet management case. SPE paper 116616. Presented at the 2008 SPE Annual Technical Conference and Exhibition, Denver, Colorado, USA, 21-24 September 2007. https://doi.org/10.2118/116616-MS 
Lee, A. S., \& Aronofsky, J. S. (1957). A linear programming model for scheduling crude oil production. SPE paper 862-G. Presented at the 32nd Annual Fall Meeting of Society of Petroleum Engineers, Dallas, Texas, 6-9 October 1957. https://doi.org/10.2118/862-G

Li, K., \& Hornr, R. N. (2003). A decline curve analysis model based on fluid flow mechanisms. SPE paper 83470. Presented at the SPE Westeren Regional/AAPG Pacific Section Joint Meeting, Long Beach, California, USA, 19-24 May 2003. https://doi.org/10.2118/83470-MS

Lianyoung, F., Junchen, L., Xiongqi, P., Xu, T., \& Lin, Z. (2008). Peak oil models forecast, Chinal's oil supply, demand. Oil and Gas Journal, 14th January 2008.

Makinde, F. A., Orodu, O. D., Ladipo, A. O., \& Anawe, P. A. L. (2012). Cumulative production forecast of an oil well using simplified "Hyperbolic-Exponential" decline models. Global Journal of Researches in General Engineering, 12(2).

Manescu, C., \& Robays, I. V. (2014). Forecasting the Brent oil price addressing time-variation in forecast performance. Working Paper Series, 1735.

Mora, O., Startzman, R. A., \& Saputelli, L. (2005). Maximizing net present value in mature gas-lift fields. SPE paper 94664. Presented at the 2005 SPE Hydrocarbon Economics and Evaluation Symposium, Dallas, Texas, USA, 3-5 April. https://doi.org/10.2118/94664-MS

Pagano, P., \& Pisani, M. (2009). Risk-adjusted forecast of oil prices. Working Paper Series, 999. Retrieved from https://econpapers.repec.org/paper/ecbecbwps/2009999.htm

Rahuma, K. M., Matug, I., \& Mahmoud, M. (2012). Decline curve analysis for Zella oil field. Petroleum and Coal, $54(3), 225-237$.

Rahuma, K. M., Mohamed, H., Hissein, N., \& Giuma, S. (2013). Prediction of reservoir performance applying decline curve analysis. International Journal of Chemical Engineering and Applications, 4(2), 74-77. https://doi.org/10.7763/IJCEA.2013.V4.266

US Energy Information Administration, www.indexmundi.com, 2014

Van Leeuwen, J., \& Chow, R. (1989). Development and application of a linear programming model to maximize cash flow for a gas field. Presented at the 40th Annual Technical Meeting of The Petroleum Society of CIM held in Banff, 28-31 May 1989. https://doi.org/10.2118/89-40-64

Vasantharajan, S., Al-Hussainy, R., \& Heinemann, R. F. (2006). Applying optimization techniques in reservoir management. Journal of Petroleum Technology.

Wang, J., Feng, L., Zhao, L., Snowden, S., \& Wang, X. (2011). A comparison of two typical multicyclic modewls used to forecast the world's conventional oil production. Energy Policy, 39(12), 7616-7621. https://doi.org/10.1016/j.enpol.2011.07.043

\section{Copyrights}

Copyright for this article is retained by the author(s), with first publication rights granted to the journal.

This is an open-access article distributed under the terms and conditions of the Creative Commons Attribution license (http://creativecommons.org/licenses/by/4.0/). 